\title{
THE THERMAL BEHAVIOUR OF THE QUADRUPOLE HYPERFINE INTERACTION IN $\left(\mathrm{NH}_{4}\right)_{2} \mathrm{HfF}_{6}$
}

\author{
J.A. MAPTTINEZ ${ }^{\star}$, P.C. RIVAS ${ }^{\star}$, M.C. CARACOCHE ${ }^{\star}$, A.M. RODRIGUEZ ${ }^{\star}$,
} A.R. LÓPEZ GARCIA 的

(Laboratorio de Interacciones Hiperfinas)

and

S. SPINELLI ${ }^{\dagger}$

\section{(Laboratorio de Rayos $X$ )}

Departmento de Fisica, Facultad de Ciencias Exactas, Universidad Nacional de La Plata, CC 67, 1900 La Plata, Argentina

Recejved 26 June 1985

(Revised 5 August 1985)

A TDPAC investigation has been accomplished on $\left(\mathrm{NH}_{4}\right)_{2} \mathrm{HfF}_{6}$ between 14 and $620 \mathrm{~K}$. A phase transition was observed below $390 \mathrm{~K}$. The low temperature phase is characterized by two non-equivalent sites for hafnium atoms in a $1: 1$ ratio. The high temperature phase, on the other hand, is depicted by a unique quadrupole interaction. Above $400 \mathrm{~K}$, the compound decomposes successively to $\mathrm{NH}_{4} \mathrm{HfF}_{s}$, $\mathrm{NH}_{4} \mathrm{Hf}_{2} \mathrm{~F}_{9}$ and $\mathrm{HFF}_{4}$. An enthalpy of $76 \pm 4 \mathrm{~kJ} / \mathrm{mol}$ could be determined for the $\left(\mathrm{NH}_{4}\right)_{2} \mathrm{HfF}_{6} \rightarrow \mathrm{NH}_{4} \mathrm{HfF}_{5}+\mathrm{NH}_{4} \mathrm{~F}$ chemical reaction. The hyperfine interaction and thermal evolution of $\left(\mathrm{NH}_{4}\right)_{2} \mathrm{HfF}_{6}$ was found to be quite similar to that of $\left(\mathrm{NH}_{4}\right)_{2} \mathrm{ZrF}_{6}$.

* Member of Carrera del Investigador Científico, CICPBA, Argentina.

* Member of Carrera del Personal de Apoyo, CONICET, Argentina.

Fellow of CONICET, Argentina.

Member of Carrera del Investigad or Cientifico, CONICET, Argentina.

$\dagger$ Fellow of CICPBA, Argentina.

() J.C. Baltzer A.G., Scientific Publishing Company 


\section{Introduction}

The ammonium hafnium hexafluoride has been studied at room temperature by Mayer et al. [1] and at $77 \mathrm{~K}$ by Gerdau et al. [2] using the time-differential perturbed angular correlation technique (TDPAC). A unique electric field gradient (EFG) was found by both authors. Their results can not be clearly connected except by assuming a strong thermal dependence of the hyperfine quadrupole interaction.

Two modifications of $\left(\mathrm{NH}_{4}\right)_{2} \mathrm{HfF}_{6}$, characterized by intense asymmetric EFGs, were observed by Gerdau et al. at $4.2 \mathrm{~K}$ using Mössbauer spectroscopy [3].

It is also known that the compound under investigation becomes unstable at moderate temperatures. Heats of decomposition for the different steps of the thermal dissociation $\left(\mathrm{NH}_{4}\right)_{3} \mathrm{HfF}_{7} \rightarrow\left(\mathrm{NH}_{4}\right)_{2} \mathrm{HfF}_{6} \rightarrow \mathrm{NH}_{4} \mathrm{HfF}_{5} \rightarrow \mathrm{Hf}_{4} \mathrm{~F}$ have already been determined [4].

Here, applying the TDPAC technique on ${ }^{181} \mathrm{Hf}$ probes, we investigate the thermal behaviour of $\left(\mathrm{NH}_{4}\right)_{2} \mathrm{HfF}_{6}$ between 14 and $620 \mathrm{~K}$ and establish, when possible, a comparison with already reported results for the isomorphous compound $\left(\mathrm{NH}_{4}\right)_{2} \mathrm{ZrF}_{6}[5,6]$.

Up to now, X-ray diffraction data as well as the crystalline structures of the $\left(\mathrm{NH}_{4}\right)_{2} \mathrm{HFF}_{6}$ compound and most of its thermolysis products are unknown. Because of this, X-ray spectra obtained in the present work have been compared with those reported for zirconium analogous compounds [7].

\section{Experimental}

The compound was prepared by adding solid $\mathrm{NH}_{4} \mathrm{~F}$ to a hot solution of $\mathrm{HfO}_{2}$ in concentrated HF. The molar ratio $\mathrm{NH}_{4} \mathrm{~F}$ to $\mathrm{HfO}_{2}$ was $2: 1$. Crystals were obtained after a slow evaporation at room temperature. Table 1 shows the diffraction data corresponding to an X-ray powder diagram taken on the as-prepared sample. These data are very similar to those reported by Gaudreau [7] for the disordered phase of $\left(\mathrm{NH}_{4}\right)_{2} \mathrm{ZrF}_{6}$.

The sample was capsulated in $0.5 \mathrm{~cm}^{3}$ sealed quartz tubes at atmospheric pressure and neutron irradiated in the RA-3 reactor of the Comision Nacional de Energía A tómica.

The high resolution TDPAC set-up $(2 \tau=0.75 \mathrm{~ns})$ and data handling which allowed us to obtain the spin rotation curves, as well as the heating and cooling systems, have been described elsewhere [6].

For the fitting procedure, we used a linear combination $\Sigma_{n} f_{n} G_{2}^{n}(t)$ of perturbing factors:

$$
G_{2}(t)=s_{20}+\sum_{i=1}^{3} s_{2 i} \exp \left(-\delta \omega_{i} t\right) \cos \left(\omega_{i} t\right),
$$


Table 1

$\mathrm{X}$-ray diffraction data for $\left(\mathrm{NH}_{4}\right)_{2} \mathrm{HfF}_{6}$

\begin{tabular}{lrrr}
\hline$d(\AA)$ & $I / I_{0}$ & $d(\AA)$ & $I / I_{0}$ \\
\hline 7.31 & 7 & 2.31 & 14 \\
6.56 & 2 & 2.21 & 2 \\
6.28 & 4 & 2.19 & 12 \\
6.07 & 4 & 2.13 & 2 \\
5.75 & 100 & 2.10 & 4 \\
5.40 & 12 & 2.07 & 2 \\
5.01 & 4 & 2.00 & 4 \\
4.57 & 2 & 1.94 & 4 \\
3.82 & 46 & 1.91 & 10 \\
3.34 & 30 & 1.90 & 14 \\
3.21 & 68 & 1.84 & 2 \\
3.14 & 6 & 1.82 & 14 \\
3.11 & 2 & 1.76 & 2 \\
2.94 & 4 & 1.72 & 4 \\
2.90 & 8 & 1.71 & 2 \\
2.62 & 2 & 1.68 & 4 \\
2.51 & 12 & 1.66 & 6 \\
2.34 & 2 & 1.61 & 4 \\
& & & \\
\hline
\end{tabular}

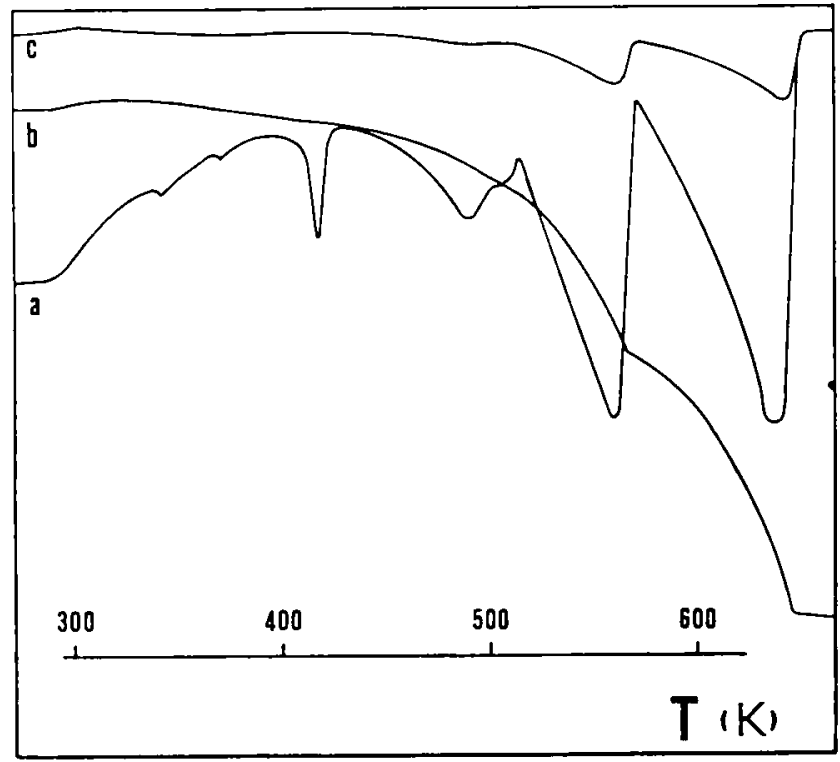

Fig. 1. Thermograms for $\left(\mathrm{NH}_{4}\right)_{2} \mathrm{HfF}_{6}$ : (a) thermal differential curve, (b) thermogravimetric curve, and (c) differential weight curve. No changes were observed at temperatures above $700 \mathrm{~K}$. 
where $s_{2 i}$ are functions of the asymmetry parameter $\eta, \omega_{i}$ depend on both $\eta$ and the quadrupole interaction frequency $\omega_{Q}$, and $\delta$ stands for a possible frequency distribution. The coefficients $f_{n}$ of the linear combination are the relative fractions of probes acted upon by each particular EFG.

Temperatures where changes could be expected were estimated via thermal differential and thermogravimetric analysis (TDA-TGA), performed between 293 and $800 \mathrm{~K}$ in air at atmospheric pressure and at a speed of $6 \mathrm{~K} / \mathrm{min}$ (fig. 1).

Whenever a modification was observed in a TDPAC spectrum at a given temperature, a non-active sample was heated at this temperature and then cooled to room temperature. An X-ray powder diagram on the treated sample was then taken in order to obtain more insight about the change.

\section{Results and discussion}

Selected spin rotation curves obtained at different temperatures are shown in fig. 2. In the range $14-293 \mathrm{~K}$ [see fig. 2(a), (b), (c)], no relevant changes were observed. Two different quadrupole interactions were needed to describe the spin rotation curves, their relative fractions keeping the ratio $1: 1$ and the frequency distributions being less than $3 \%$ over all the thermal range. Figure 3 shows the thermal behaviour of the fitted quadrupole frequencies and asymmetry parameters. When the asymmetry parameter that grows with temperature ( $\boldsymbol{\Lambda}$ in fig. 3 ) approaches its maximum value $(\eta \rightarrow 1)$, the two-site picture describing the interaction begins to be replaced by a simpler one corresponding to a single, symmetric and non-distributed interaction with $\omega_{Q}=199 \pm 2 \mathrm{Mrad} / \mathrm{s}$. Figure 2(d) exhibits the spin rotation curve obtained at $390 \mathrm{~K}$, which was fitted with $70 \%$ of the interaction just mentioned and $30 \%$ of the one depicting the lower temperature range $14-293 \mathrm{~K}$. TDA and TGA results showed a sharp endothermic peak centered at $415 \mathrm{~K}$ and no relevant loss of weight, respectively. The change evidenced in the spin rotation curve was assumed to be due to the phase transition $\alpha-\left(\mathrm{NH}_{4}\right)_{2} \mathrm{HfF}_{6} \rightarrow \beta-\left(\mathrm{NH}_{4}\right)_{2} \mathrm{HfF}_{6}$, in analogy with that of $\left(\mathrm{NH}_{4}\right)_{2} \mathrm{ZrF}_{6}[6,8]$.

The $430 \mathrm{~K}$ spectrum [fig. 2(e)] was fitted with two interactions: the one corresponding to $\beta$ - $\left(\mathrm{NH}_{4}\right)_{2} \mathrm{HfF}_{6}$ and another characterized by $\omega_{Q}=66 \pm 1 \mathrm{Mrad} / \mathrm{s}$, $\eta=0.02 \pm 0.02$ and $\delta=(13 \pm 2) \%$. Complementary information from TDA, TGA and $\mathrm{X}$-ray spectra indicated that the reaction $\beta-\left(\mathrm{NH}_{4}\right)_{2} \mathrm{HfF}_{6} \rightarrow \mathrm{NH}_{4} \mathrm{HfF}_{5}+\mathrm{NH}_{4} \mathrm{~F}$ had taken place. Thus, the quadrupole interaction parameters just reported belong to $\mathrm{NH}_{4} \mathrm{HfF}_{5}$.

Regarding the mentioned decomposition, we have calculated the equilibrium constant $K_{\mathrm{X}}$ for this reaction as indicated in ref. [6]: $K_{\mathrm{X}}=f^{2} /\left(1-f^{2}\right), f$ being the relative fraction of $\mathrm{NH}_{4} \mathrm{HfF}_{5}$. Results versus the reciprocal temperature are plotted in fig. 4 , together with those reported for the $\left(\mathrm{NH}_{4}\right)_{2} \mathrm{ZrF}_{6}$ decomposition. An enthalpy of $(76 \pm 4) \mathrm{kJ} / \mathrm{mol}$ was determined. The agreement with that deduced for the isomorphous zirconium compound, $(82 \pm 6) \mathrm{kJ} / \mathrm{mol}$, is remarkable. 

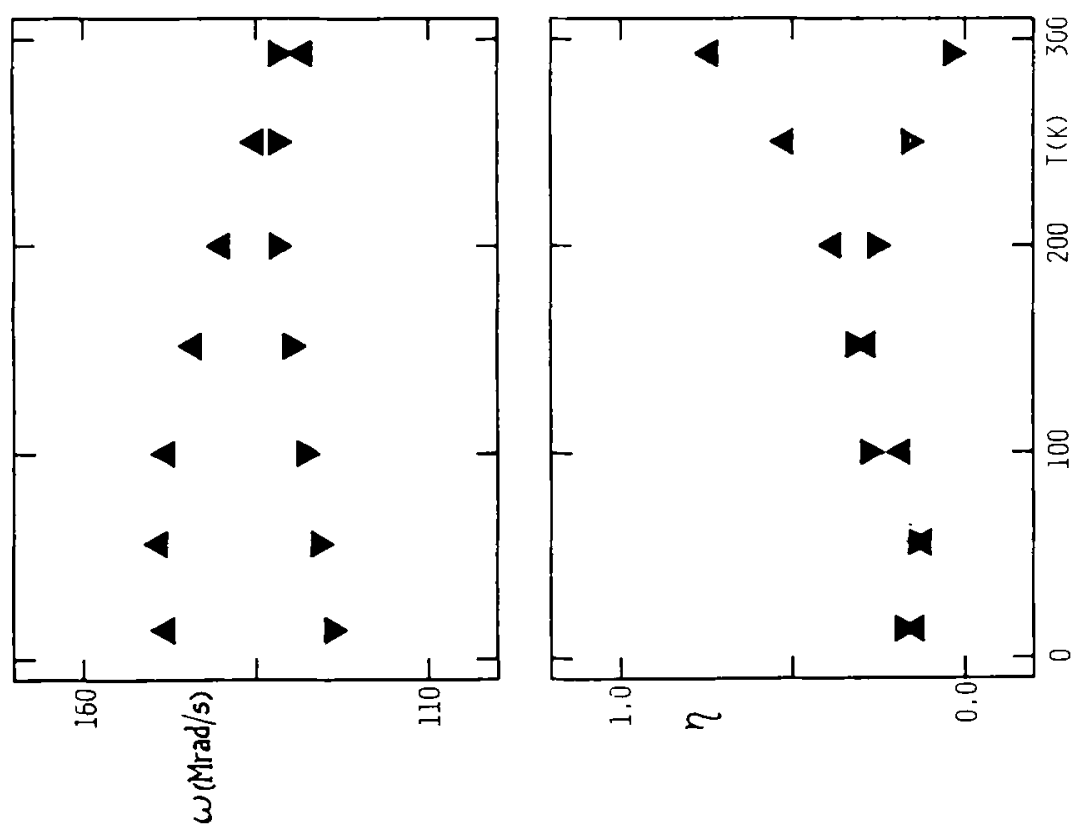

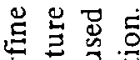

跑娄

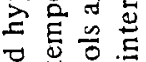

$\pm 0$

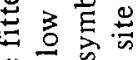

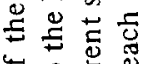

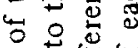

5 舫

음

吾空

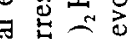

焉焉

ㄴㅎㅎ

$m$ E

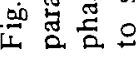

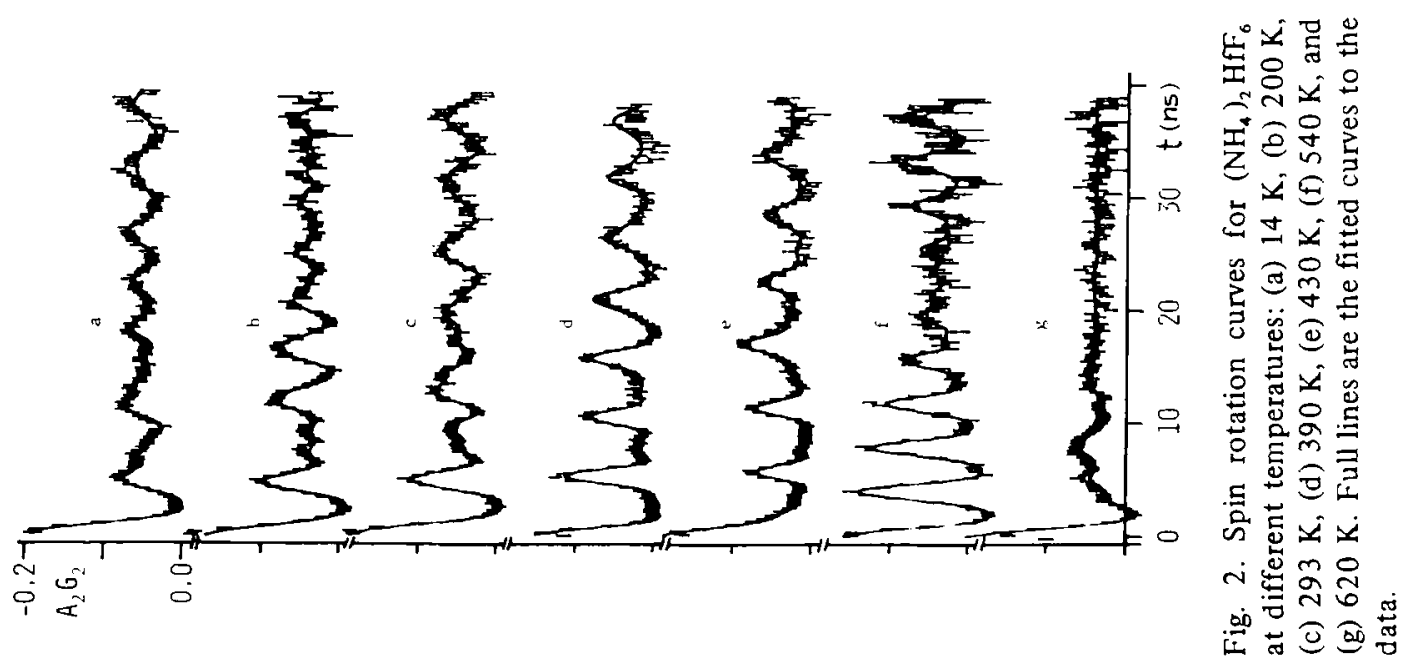




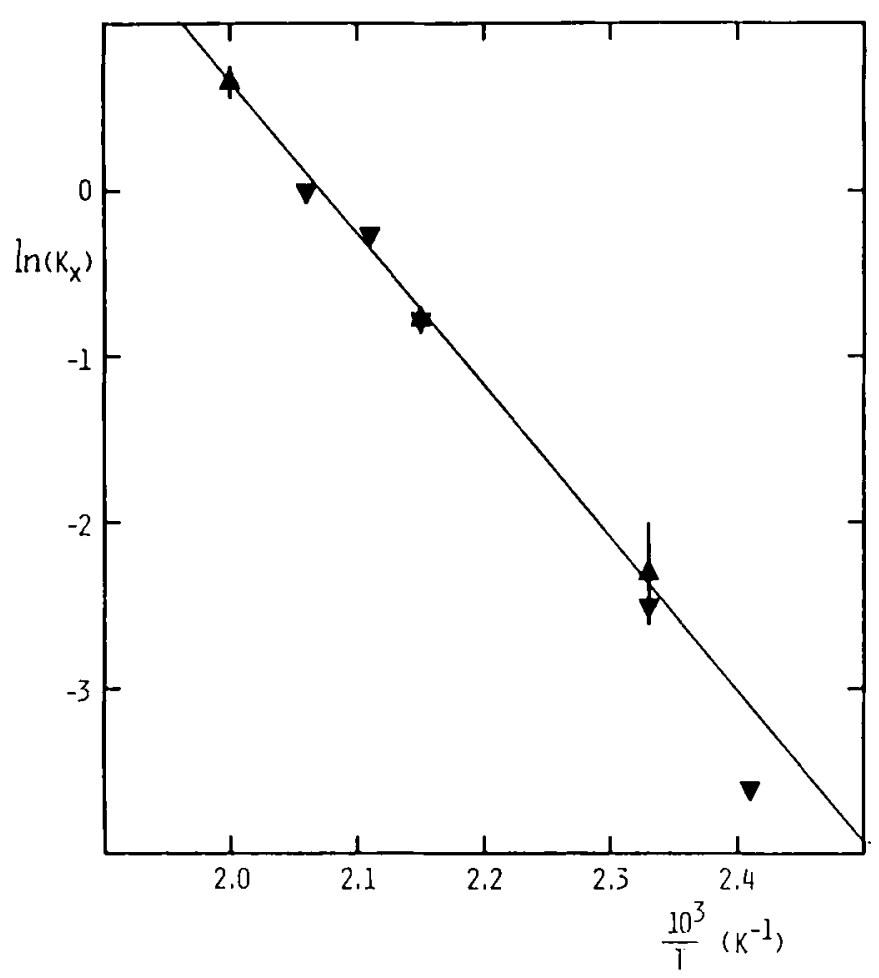

Fig. 4. Experimental equilibrium constant versus reciprocal temperature. $\triangle:\left(\mathrm{NH}_{4}\right)_{2} \mathrm{HfF}_{6}$ to $\mathrm{NH}_{4} \mathrm{HfF}_{5}$ reaction, $\nabla:\left(\mathrm{NH}_{4}\right)_{2} \mathrm{ZrF}_{6}$ to $\mathrm{NH}_{4} \mathrm{ZrF}_{5}$ reaction. The value at $500 \mathrm{~K}$ was calculated on the hypothesis that the reaction giving rise to $\mathrm{NH}_{4} \mathrm{Hf}_{2} \mathrm{~F}_{9}$ had not yet begun.

That fact that at $500 \mathrm{~K}$ the typical interaction of $\mathrm{NH}_{4} \mathrm{Hf}_{2} \mathrm{~F}_{9}$ [9] appeared in the spin rotation curves, reaching $100 \%$ of the relative fraction at $540 \mathrm{~K}$ [fig. $2(\mathrm{f})$ ], allowed us to state that a new reaction had taken place in the sample.

The $\mathrm{NH}_{4} \mathrm{Hf}_{2} \mathrm{~F}_{9}$ quadrupole interaction remained up to $620 \mathrm{~K}$, where it changed into that of $\mathrm{HfF}_{4}$ [fig. 2(g)] [10].

Sets of quadrupole hyperfine parameters associated to all compounds involved in this work are shown in table 2 .

Thermal analysis above $415 \mathrm{~K}$ (see fig. 1) can now be clearly interpreted. The peaks appearing in TDA are related to the successive steps of the $\beta-\left(\mathrm{NH}_{4}\right)_{2} \mathrm{HfF}_{6}$ $\rightarrow \mathrm{NH}_{4} \mathrm{HfF}_{5} \rightarrow \mathrm{NH}_{4} \mathrm{Hf}_{2} \mathrm{~F}_{9} \rightarrow \mathrm{HfF}_{4}$ decomposition.

Finally, it is interesting to mention that some of the active samples did not exhibit at room temperature the characteristic spin rotation curve shown in fig. 2(c). The thermal behaviour of the corresponding quadrupole interaction is not yet clearly understood. Investigations to elucidate this duality are in progress. 
Table 2

\begin{tabular}{|c|c|c|c|c|c|}
\hline Compound & $T(\mathrm{~K})$ & & $V_{z z}\left(10^{17} \mathrm{~V} / \mathrm{cm}^{2}\right)$ & $\eta$ & $\delta(\%)$ \\
\hline & & site 1 & $13.52 \pm 1.62$ & $0.87 \pm 0.01$ & $1 \pm 1$ \\
\hline \multirow[t]{2}{*}{$\alpha-\left(\mathrm{NH}_{4}\right)_{2} \mathrm{HfF}_{6}$} & 293 & & & & \\
\hline & & site 2 & $13.94 \pm 1.67$ & $0.52 \pm 0.01$ & $1 \pm 1$ \\
\hline$\beta-\left(\mathrm{NH}_{4}\right)_{2} \mathrm{HfF}_{6}$ & 390 & & $20.85 \pm 2.50$ & $0.05 \pm 0.02$ & $2 \pm 1$ \\
\hline \multirow[t]{2}{*}{$\mathrm{NH}_{4} \mathrm{HfF}_{5}$} & 430 & & $6.92 \pm 0.83$ & $0.02 \pm 0.02$ & $13 \pm 2$ \\
\hline & & site 1 & $15.93 \pm 1.91$ & $0.89 \pm 0.01$ & $1 \pm 1$ \\
\hline \multirow[t]{2}{*}{$\mathrm{NH}_{4} \mathrm{Hf}_{2} \mathrm{~F}_{9}$} & 540 & & & & \\
\hline & & site 2 & $28.19 \pm 3.38$ & - $0^{\star}$ & $11 \pm 3$ \\
\hline $\mathrm{HfF}_{4}$ & 620 & & $13.31 \pm 1.60$ & $0.34 \pm 0.04$ & $15 \pm 3$ \\
\hline
\end{tabular}

Fitted values of the quadrupole hyperfine parameters associated to the different compounds investigated. The reported data correspond to temperatures where the abundance of each compound was maximum. A quadrupole moment $Q=2.53 \mathrm{~b}$ has been used for the derivation of $V_{z z}$. cates fixed parameter.

\section{Conclusions}

The TDPAC technique applied to the study of the $\left(\mathrm{NH}_{4}\right)_{2} \mathrm{HfF}_{6}$ allowed us to draw the following conclusions:

(a) At room temperature, the $\left(\mathrm{NH}_{4}\right)_{2} \mathrm{HfF}_{6}$ presents a crystalline phase having two non-equivalent sites for hafnium positions in a ratio $1: 1$. A phase transition to a single-site lattice occurs at moderate temperatures.

(b) Above $400 \mathrm{~K}$, the compound decomposes to $\mathrm{NH}_{4} \mathrm{HfF}_{5}, \mathrm{NH}_{4} \mathrm{Hf}_{2} \mathrm{~F}_{9}$ and $\mathrm{HfF}_{4}$ at approximately $415 \mathrm{~K}, 465 \mathrm{~K}$, and $600 \mathrm{~K}$, respectively.

(c) The enthalpy of decomposition for the reaction $\beta-\left(\mathrm{NH}_{4}\right)_{2} \mathrm{HfF}_{6}$ $\rightarrow \mathrm{NH}_{4} \mathrm{HfF}_{5}+\mathrm{NH}_{4} \mathrm{~F}$ was determined to be very close to that reported for the equivalent reaction in the zirconium compound.

(d) The hyperfine interaction evolutions of hafnium and zirconium compounds exhibit a perfect analogy.

\section{Acknowledgements}

The authors are indebted to the TECNOPU group at CNEA which supplied the thermograms, and to Dr. G. Punte for the obtainment of the X-ray powder diagrams. Partial financial support by CONICET, CICPBA and SUBCyT (Argentina) and Kernforschungszentrum Karlsruhe GmbH (West Germany) is also gratefully acknowledged. 


\section{References}

[1] L. Mayer, E. Bodenstedt and C. Günther, Z. Phys, 177(1964)28.

[2] E. Gerdau, J. Wolf, H. Winkler and J. Braunsfurth, Proc. Roy. Soc. A311(1969)197.

[3] E. Gerdau, B. Scharnberg and H. Winkler, in: Hyperfine Interactions in Excited Nuclei (Gordon and Breach, New York, 1971) p. 861.

[4] M.A. Mikhailov, D.G. Epov and E.G. Rakov, Russ. J. Inorg. Chem. 18(1973)56.

[5] A.M. Rodriguez, J.A. Martinez, M.C. Caracoche, P.C. Rivas and A.R. López García, Hyp. Int. 14(1983)227.

16] A.M. Rodríguez, J.A. Martinez, M.C. Caracoche, P.C. Rivas, A.R. López García and S. Spinelli, J. Chem. Phys. 82(1985)1271.

[7] B. Gaudreau, Rev. Chim. Minérale 2(1965)1.

[8] H. Hull and A.G. Tumbull, J. Inorg. Nucl. Chem. 29(1967)951.

[9] J.A. Martinez, M.C. Caracoche, A.M. Rodriguez, P.C. Rivas and A.R. López García, Hyp. Int. 14(1983)135.

[10] J.A. Martinez, M.C. Caracoche, A.M. Rodríguez, P.C. Rivas and A.R. López Garcia, Chem. Phys. Lett. 102(1983)277. 